\title{
Long-term results of anatomic correction for congenitally corrected transposition of the great arteries: A 19-year experience
}

\author{
Christian P. Brizard, MD, MS, ${ }^{\mathrm{a}, \mathrm{b}, \mathrm{c}}$ Alice Lee, MD, BBiomed, ${ }^{\mathrm{b}}$ Diana Zannino, MSc, ${ }^{\mathrm{c}}$ \\ Andrew M. Davis, MBBS, MD, ${ }^{\mathrm{b}, \mathrm{c}, \mathrm{d}}$ Tyson A. Fricke, MBBS, BMedSc, ${ }^{\mathrm{b}}$ Yves d'Udekem, MD, PhD, ${ }^{\mathrm{a}, \mathrm{b}, \mathrm{c}}$ \\ Igor E. Konstantinov, MD, PhD, ${ }^{\mathrm{a}, \mathrm{b}, \mathrm{c}}$ Johann Brink, MD, ${ }^{\mathrm{a}}$ and Michael M. H. Cheung, MBChB ${ }^{\mathrm{b}, \mathrm{c}, \mathrm{d}}$
}

\begin{abstract}
Objective: The surgical indication, timing, strategy, and surgical technique for anatomic correction of congenitally corrected transposition of the great arteries are challenging. We evaluated the long-term results at The Royal Children's Hospital Melbourne.
\end{abstract}

Methods: Review of 32 successive anatomic corrections between 1996 and 2015.

Results: Twenty-one double-switch (66\%), 6 Senning/Bex-Nikaidoh (19\%), and 5 Senning/Rastelli (16\%) procedures were performed (median age, 1.9 years). Median follow-up was 5.4 years with 4 deaths and 1 heart transplant. Cumulative incidence of late reoperation was $8 \%, 29 \%$, and $59 \%$ at 1,5 , and 10 years, respectively. Twenty-six patients had full follow-up with native hearts. Nineteen had normal left ventricle (LV) function. Late LV dysfunction, mostly mild, was not related to needing a pacemaker $(P=.4)$ or a pulmonary artery band (PAB) $(P=.08)$. Previous PAB was linked to the need for aortic valve surgery or neoaortic regurgitation moderate or greater $(P=.03)$. Six required Senning revision. The introduction of the Shumacker modification of the Senning has generated stable pulmonary venous pathways. Six patients developed postoperative iatrogenic atrioventricular block dependent on a permanent pacemaker.

Conclusions: Anatomic correction is a surgical challenge. It provides excellent functional outcomes in survivors with a significant need for reoperation and a definite risk of death or transplantation. Normal LV function should be expected in most patients. LV dysfunction was not linked to PAB or pacemaker requirement but surgery without LV training had better long-term LV function. The Shumacker modification provided stable venous pathways. Iatrogenic atrioventricular block remains a challenge. (J Thorac Cardiovasc Surg 2017;154:256-65)

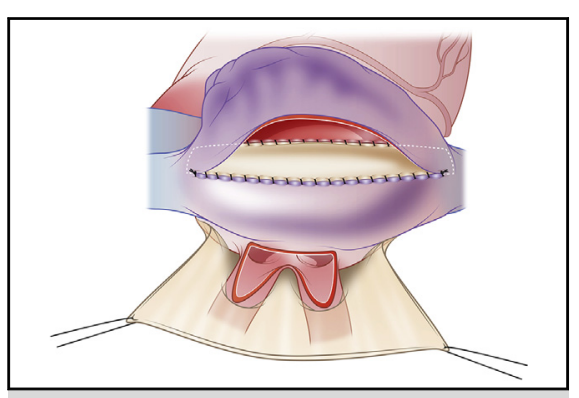

Senning modification according to Shumacker creating large compliance venous chambers.

\section{Central Message}

Anatomic correction for congenitally corrected transposition of the great arteries is a complex surgery. It provides excellent functional outcomes in survivors.

\section{Perspective}

Understanding the long-term results of anatomic correction for congenitally corrected transposition of the great arteries allows for improvement in the consideration of timing, strategy, and technical details of the surgery in these patients. This will subsequently improve patient outcomes in our center and others.

See Editorial Commentary page 266.
Symptoms or evidence of declining cardiac function in patients with congenitally corrected transposition of the great

From the ${ }^{\mathrm{a} C a r d i a c}$ Surgery Unit and ${ }^{\mathrm{d}}$ Department of Cardiology, Royal Children's Hospital; ${ }^{\mathrm{b}}$ The University of Melbourne; and ${ }^{\mathrm{c}}$ Murdoch Children's Research Institute, Parkville, Victoria, Australia.

Read at the 96th Annual Meeting of The American Association for Thoracic Surgery, Baltimore, Maryland, May 14-18, 2016.

Received for publication May 25, 2016; revisions received Jan 19, 2017; accepted for publication March 5, 2017; available ahead of print May 2, 2017.

Address for reprints: Christian P. Brizard, MD, MS, Cardiac Surgery Unit, Royal Children's Hospital, Parkville, VIC 3052, Australia (E-mail: christian.brizard@ rch.org.au).

0022-5223/\$36.00

Copyright (c) 2017 by The American Association for Thoracic Surgery

http://dx.doi.org/10.1016/j.jtcvs.2017.03.072 arteries (ccTGA) require surgical management to control the evolution of cardiac failure. The results of physiologic correction maintaining a systemic right ventricle (RV) have been poor, ${ }^{1-3}$ whereas anatomic correction surgery restores the morphologic left ventricle (LV) and mitral valve (MV) into their systemic role. ${ }^{4}$ The literature

Scanning this QR code will take you to the supplemental tables, figures, and video for this article. 


$$
\begin{aligned}
& \text { Abbreviations and Acronyms } \\
& \begin{aligned}
\text { AR } & =\text { aortic regurgitation } \\
\text { ccTGA } & =\text { congenitally corrected transposition of } \\
& \text { the great arteries } \\
\text { CHB } & \text { complete heart block } \\
\text { LV } & =\text { left ventricle } \\
\text { LVOT } & =\text { left ventricular outflow tract } \\
\text { MR } & =\text { mitral regurgitation } \\
\mathrm{MV} & =\text { mitral valve } \\
\text { neo-AV } & =\text { neoaortic valve } \\
\text { PAB } & =\text { pulmonary artery band } \\
\text { PPM } & =\text { permanent pacemaker } \\
\text { RCH } & =\text { Royal Children's Hospital } \\
\text { RV } & =\text { right ventricle } \\
\text { TR } & =\text { tricuspid regurgitation } \\
\text { TV } & =\text { tricuspid valve } \\
\text { VSD } & =\text { ventricular septal defect }
\end{aligned}
\end{aligned}
$$

surrounding this procedure is expanding. The procedure combines the correction of the atrioventricular discordance using an atrial switch (Senning procedure at The Royal Children's Hospital $[\mathrm{RCH}]$ ), and simultaneously the correction of ventriculoarterial discordance. Thus, the combined techniques are the Senning-arterial switch or doubleswitch, Senning-Rastelli procedure, and Senning-Bex/ Nikaidoh procedure.

This study aimed to contribute to the body of knowledge and to further refine the surgical indication, timing, and pitfalls of anatomic correction of ccTGA by reviewing our experience during the past 19 years.

\section{METHODS}

\section{Study Population}

This study was reviewed and approved by the RCH Human Research Ethics Committee (reference No. 34184A). The need for patient consent was waived due to the retrospective nature of the study.

ccTGA was defined as patients with discordant atrioventricular and ventriculoarterial connections. Morphologic diagnoses of patients were established by 2-dimensional echocardiography and confirmed at surgery. The hospital database was screened to identify patients with a diagnosis of ccTGA or synonymous terms. Of 84 children known to $\mathrm{RCH}$ with this diagnosis up to August 2015, 32 patients had undergone 1 of 3 anatomic correction procedures from 1996 onward at $\mathrm{RCH}$ and were included in this study (Figure E1). Twenty-seven patients with ccTGA had their decisive surgery during the same time span. There were 16 Fontan procedures for unbalanced ventricles, 7 Fontan procedures for unsuitable anatomy for repair, and 4 physiologic repairs.

\section{Follow-up}

Preoperative, operative, and follow-up data on the patients were collected from hospital databases and from referring cardiologists between March and November 2015. One international patient was lost to follow-up.

An objective review of incomplete echocardiographic reports was obtained from a cardiologist at $\mathrm{RCH}$. The severity of valvular regurgitation was graded from 0 (none), 1 (trivial), 2 (mild), 3 (moderate), to 4 (severe). ${ }^{5}$
Subjective evaluation of LV function was utilized when no objective measure was recorded. For those studies where an objective measure of ejection fraction was available, we used the correlation of normal function for ejection fraction $>51 \%$, mild dysfunction $41 \%$ to $50 \%$, moderate dysfunction $31 \%$ to $40 \%$, and severe dysfunction $\leq 30 \%$.

\section{Statistical Analysis}

All data were exported to and analyzed using IBM SPSS Statistics version 22.0 (IBM-SPSS Inc, Armonk, NY) and R version 3.1.3 (R Foundation for Statistical Computing, Vienna, Austria). Continuous variables were reported as median and range and/or interquartile range (IQR). Categorical variables were reported as counts and associated percentages. Analyses between categorical variables employed 2-sided Pearson $\chi^{2}$ tests. Competing risks survival methods were used to describe the cumulative incidence of the event of late reintervention and reoperation with death and heart transplantation as the competing risks. Kaplan-Meier curves were used to describe freedom from death or heart transplantation following anatomic correction. Cox proportional hazards models and likelihood ratio tests were used to assess the association of prior pulmonary artery band with the event of aortic valve surgery or neoaortic valve (neo-AV) regurgitation moderate or greater, and the effect of age at surgery (in years), permanent pacemaker insertion (time-varying covariate), and prior pulmonary artery band (PAB) with the event of reduced LV function at follow-up postanatomic correction. Event rates at 1, 5, and 10 years were reported with corresponding $95 \%$ confidence intervals (CIs). No multivariate analysis was performed due to the small numbers of events.

\section{Definitions}

Early death, reintervention, or reoperation was defined as occurring before hospital discharge or within 30 days of surgery. Late death, reintervention, or reoperation was defined as occurring after discharge and more than 30 days after surgery.

Permanent pacemaker (PPM) placement is the first instance of PPM placement. PPM revision is a change in pacemaker leads or generator box at any time after initial PPM placement.

\section{RESULTS}

\section{Morphologic Data}

There were 18 male patients $(56 \%)$. Characteristics of the patients are detailed in Table 1 . Twenty-nine patients (91\%) had situs solitus, $2(6 \%)$ patients had situs inversus, and 1 had left isomerism (3\%). This latter patient was kept in the series because he underwent an anatomic correction procedure. Coronary anatomy was confirmed as 1LADCX2R in $19(59 \%)$ patients.

A ventricular septal defect (VSD) was present in 25 patients $(78 \%) ; 13$ patients had associated pulmonary or subpulmonary stenosis, and 12 patients had no pulmonary circulation protection. Eight $(25 \%)$ patients had features of Ebstein's anomaly of the tricuspid valve (TV).

Nine patients $(28 \%)$ had a conduction anomaly before corrective surgery. One had acquired complete heart block (CHB) following a palliative procedure performed outside the RCH (LV outflow tract [LVOT] resection), 3 had complete heart block, 4 had second-degree heart block, and 1 had first-degree heart block.

Preoperatively, 31 (97\%) patients had normal LV function and $27(84 \%)$ had normal RV function. Seven (22\%) patients had moderate or greater tricuspid regurgitation (TR). No 
TABLE 1. Patient characteristics stratified by type of anatomic correction

\begin{tabular}{|c|c|c|c|}
\hline Characteristic & Double switch $(n=21)(\%)$ & Senning-Rastelli $(\mathbf{n}=5)(\%)$ & Senning-Bex/Nikaidoh $(n=6)(\%)$ \\
\hline \multicolumn{4}{|l|}{ Demographic } \\
\hline \multicolumn{4}{|l|}{ Sex } \\
\hline Male & $11(52)$ & $2(40)$ & $5(83)$ \\
\hline Female & $10(48)$ & $3(60)$ & $1(17)$ \\
\hline \multicolumn{4}{|l|}{ Congenital cardiac anomalies } \\
\hline VSD & $14(67)$ & $5(100)$ & $6(100)$ \\
\hline IVS & $7(33)$ & $0(0)$ & $0(0)$ \\
\hline PS & $3(14)$ & $1(20)$ & $6(100)$ \\
\hline Pulmonary atresia & $0(0)$ & $4(80)$ & $0(0)$ \\
\hline Ebsteinoid features of TV & $8(38)$ & $0(0)$ & $0(0)$ \\
\hline Congenital heart block & $8(38)$ & $0(0)$ & $0(0)$ \\
\hline $\mathrm{CoA}$ & $2(10)$ & $0(0)$ & $0(0)$ \\
\hline Hypoplastic aortic arch & $1(5)$ & $0(0)$ & $0(0)$ \\
\hline \multicolumn{4}{|l|}{ Situs } \\
\hline Solitus & $21(100)$ & $4(80)$ & $4(67)$ \\
\hline Inversus & $0(0)$ & $1(20)$ & $1(17)$ \\
\hline Isomerism & $0(0)$ & $0(0)$ & $1(17)$ \\
\hline
\end{tabular}

patients had greater than mild aortic regurgitation (AR), mitral regurgitation (MR), or pulmonary regurgitation.

Twelve patients (all double-switch with requirement for $\mathrm{LV}$ retraining) underwent a cardiac catheterization procedure before corrective surgery. The preoperative LV/RV pressure was close to 0.7 or above in all patients but 1 patient (0.56). Six patients also underwent preoperative cardiac magnetic resonance imaging. All had an indexed LV mass below the normal lower limit of $63 \mathrm{~g} / \mathrm{m}^{2}$ (mean, $41.67 \pm 11.55 \mathrm{~g} / \mathrm{m}^{2}$ ).

\section{Procedures Before Anatomic Correction}

Twenty $(63 \%)$ patients underwent surgical procedures before anatomic correction. They are included in Table 2. Median age at first palliation was 0.12 years (range, 0.0111.12 years).

Twelve patients (38\%) (all double-switch) received a PAB. Median age at placement of first PAB was 0.23 years (range, 0.01-11.1 years), and the median time from first PAB placement to anatomic correction surgery was 1.5 years (range, 0.04-4.2 years). The purpose of the band was LV retraining (10 patients) or control of pulmonary blood flow ( 2 patients). Three patients required PAB tightening at a subsequent procedure.

Pacemakers were placed in $5(16 \%)$ patients before anatomic correction. Four were placed for the patients with CHB ( 3 congenital and 1 iatrogenic during palliation), and 1 was placed for a patient with symptomatic seconddegree heart block.

\section{Anatomic Correction}

Primary correction was achieved in 12 patients $(38 \%)$. Median age at anatomic correction was 1.9 years (range, 0.1-13.5 years; IQR, 0.8-5.1), and median weight was
$11.1 \mathrm{~kg}$ (range, 3.8-57.7 kg; IQR, 7.4-20.1). Twenty-one patients $(66 \%)$ underwent the double-switch procedure, 5 patients $(16 \%)$ underwent Senning-Rastelli procedure, and 6 patients $(19 \%)$ underwent Senning-Bex/Nikaidoh procedure. Of 21 patients who underwent the double-switch, 14 had a VSD, and 7 had an intact ventricular septum. All 5 patients who underwent the Senning-Rastelli procedure had VSD and pulmonary stenosis; all had an earlier palliation with Blalock-Taussig shunt placement. All 6 SenningBex/Nikaidoh patients had a VSD and pulmonary stenosis; 3 were shunted before. Indications for surgery have been stratified by surgery type in Table 2 .

Eight patients received a sutureless Senning modification of the Shumacker technique (2 double-switch, 2 SenningRastelli, and 3 Senning-Bex/Nikaidoh) ${ }^{6}$ (Figure 1 and Video 1). The Lecompte maneuver was used in 16 patients (15 double-switch and 1 Senning-Bex/Nikaidoh). The median cardiopulmonary bypass and aortic crossclamp times were 333 minutes (range, 184-558 minutes; IQR, 280431) and 210 minutes (range, 113-378 minutes; IQR, 185283), respectively.

Table E1 details concomitant procedures during the anatomical correction. Twenty-four of 25 patients with VSD $(96 \%)$ had a VSD closure. Two pacemakers were placed $(6 \%)$ for preoperative second-degree atrioventricular block. Pulmonary artery repair or reconstruction was performed in $4(13 \%)$ patients. There were 4 instances of intraoperative valve repair $(1,2$, and 1 instances of TV, $\mathrm{MV}$, and pulmonary valve repair, respectively). Two Senning-Bex/Nikaidoh patients had straddling MV requiring reimplantation of part or whole of 1 papillary muscle into the LV and 2 Senning-Bex/Nikaidoh patients had double translocation (ie, translocation of the pulmonary root). 
TABLE 2. Indication for corrective procedure and previous palliations

\begin{tabular}{|c|c|c|c|}
\hline Corrective procedure & Previous palliations & Indication & Notes \\
\hline \multirow[t]{21}{*}{ Double-switch } & $\mathrm{PAB}, \mathrm{PM}$ & Severe TR at early age & - \\
\hline & - & Severe TR at early age & - \\
\hline & - & Elective at $2-3 \mathrm{mo}(\mathrm{w} / \mathrm{o} \mathrm{PAB})$ & - \\
\hline & PAB (shunt control), PM & Symptomatic & - \\
\hline & - & Severe TR at early age, LV untrained & LVAD postoperative \\
\hline & - & Elective at 2-3 mo (w/o PAB) & ECMO postoperative \\
\hline & - & Elective at 2-3 mo (w/o PAB) & - \\
\hline & - & Elective, LV $60 \%$ systemic & LVAD postoperative \\
\hline & PAB & LV trained & - \\
\hline & PAB (shunt control), PDA lig & Elective & - \\
\hline & $\mathrm{PAB}$, aortic arch repair, PDA lig & LV trained & - \\
\hline & $\mathrm{PAB}$ & LV trained & - \\
\hline & BT shunt & Elective & - \\
\hline & $\mathrm{PAB}$, coarctation repair & LV trained & - \\
\hline & $\mathrm{PAB}, \mathrm{PM}$ & LV incompletely trained & LVAD postoperative \\
\hline & - & Elective & - \\
\hline & $\mathrm{PAB}, \mathrm{PM}$ & LV trained & - \\
\hline & - & Severe TR & - \\
\hline & $\mathrm{PAB}$ & LV trained & - \\
\hline & PAB, PDA lig, LVOT resection, PM & LV trained, poor RV and LV function & - \\
\hline & $\mathrm{PAB}$ & LV trained & LVAD postoperative \\
\hline \multirow[t]{5}{*}{ Senning-Rastelli } & BT shunt, PDA lig, LPA patch & Symptomatic & - \\
\hline & BT shunt & Elective & - \\
\hline & BT shunt, PDA lig, LPA patch & Elective & - \\
\hline & BT shunt & Elective & - \\
\hline & BT shunt $\times 2$ & Symptomatic & - \\
\hline \multirow[t]{6}{*}{ Senning-Bex/Nikaidoh } & BT shunt & Elective & - \\
\hline & - & Symptomatic & - \\
\hline & BT shunt & Elective (previous palliations) & - \\
\hline & - & Symptomatic & - \\
\hline & - & Symptomatic & - \\
\hline & - & Elective & - \\
\hline
\end{tabular}

$P A B$, Pulmonary artery band; $P M$, pacemaker; $T R$, tricuspid regurgitation; $w / o$, without; $L V$, left ventricle; $L V A D$, left ventricular assist device; $E C M O$, extracorporeal membrane oxygenation; $P D A$ lig, patent ductus arteriosus ligation; $B T$, Blalock-Taussig; $L V O T$, left ventricular outflow tract; $R V$, right ventricle; $L P A$, left pulmonary artery.

Two double-switch patients required neo-aortic mechanical valve replacement. One neo-AV had been damaged at the time of initial palliation (LVOT resection). For the other patient, the neoaortic root was extremely distended and a transoesophageal echocardiogram at the end of the operation demonstrated significant AR. The valve was not salvageable and required immediate replacement.

There was no operative mortality. During the early postoperative period, $4(13 \%)$ double-switch patients required a left ventricular assist device. This was indicated for completion of LV training in 3 patients. One patient $(3 \%)$ required extracorporeal membrane oxygenation for impossibility to wean bypass. The chest was left open in 12 patients $(38 \%)$. Two patients $(6 \%)$ had cardiac tamponade, 7 patients $(22 \%)$ had drainage of pleural effusion, and $4(13 \%)$ had chylothorax managed conservatively. One emergency mediastinal exploration for bleeding was performed.

Median intensive care unit stay was 5.3 days (range, 1.6-36.5 days; IQR, 2-8.8), and median intermittent positive-pressure ventilation time was 79 hours (range, 4-778 hours; IQR, 32.5-176.2). Median hospital stay length was 16 days (range, 5-121 days; IQR, 9-22.5).

\section{Early Reoperation}

Ten patients required cardiac-related early reoperation. Seven were pacemaker placements due to development of iatrogenic CHB (5 dual-chamber pacemakers, 1 cardiac resynchronization therapy, and 1 ventricular pacemaker backup not used because the child regained normal sinus rhythm) across 3 double-switch, 2 Senning-Bex/Nikaidoh, and 2 Senning-Rastelli procedures with no differences across the 3 surgery types. There was 1 pacemaker revision and 1 Senning revision. One patient required MV repair, and 1 patient required aortic valve repair secondary to moderate AR.

\section{Late Reinterventions and Reoperations}

Ten patients had late reoperations after anatomic correction (Table 3). Eleven PPM revisions occurred across 7 of these patients. If PPM revisions are excluded, overall 7 

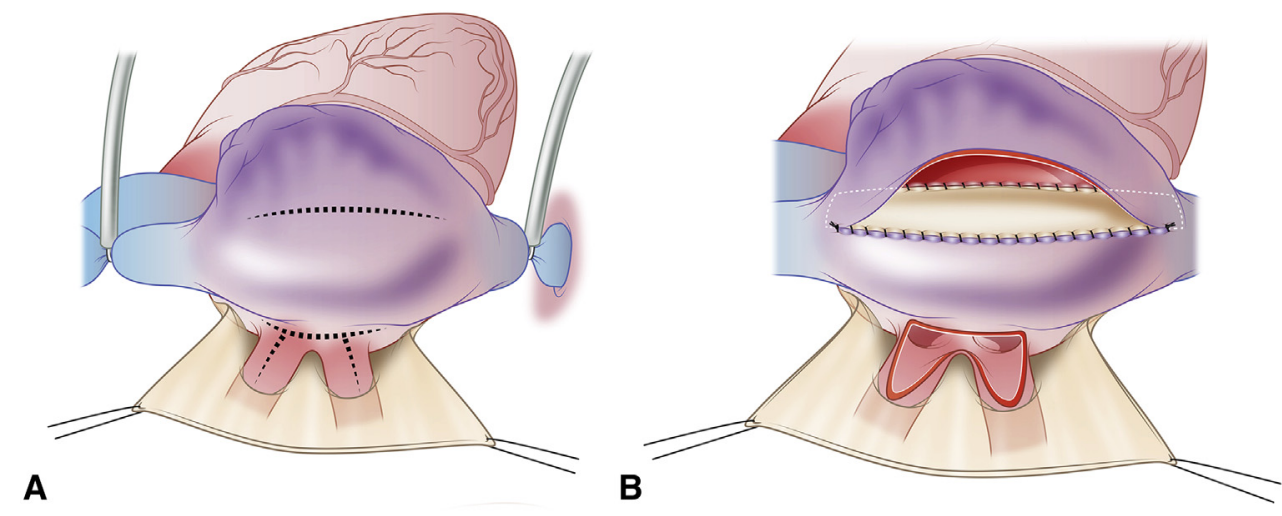

C
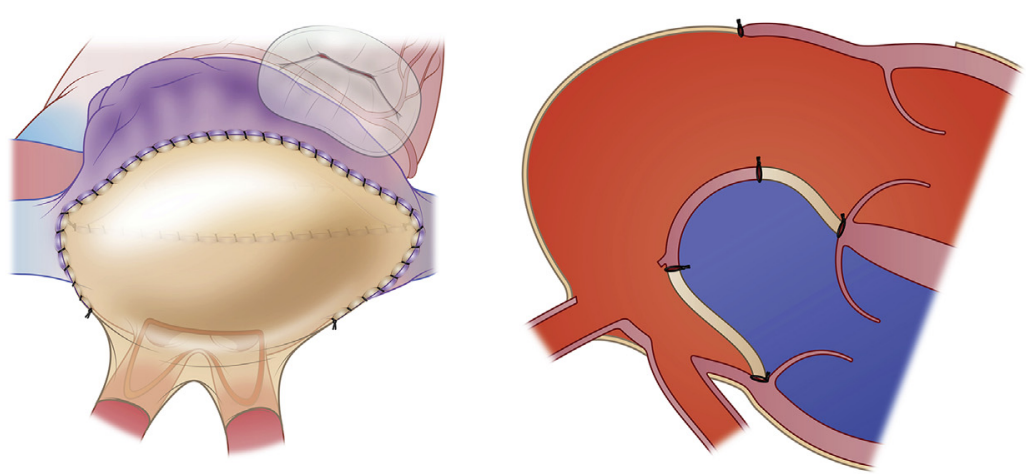

FIGURE 1. Senning modification according to the Shumacker modification (Illustrated by Bill Reid). A, Atrial incisions. Horizontal on the right atrium, at the level of the superior edge of the superior and inferior vena cava. On the left atrium, horizontal immediately below the interatrial groove with minimal dissection of the latter; two perpendicular incisions on the superior aspect of the right pulmonary veins and excision of the edges to create a large orifice, larger than the required mitral valve size for the body surface area. B, Augmentation of the systemic venous channel with a long patch. C, Left, Rotation of the rightward aspect of the pericardium creates the inferior aspect of the pulmonary venous channel. The inferior aspect is totally sutureless. Right, Schematic horizontal cut demonstrating the enlarged compared with a classic Senning.

of 10 patients required other late reoperations ( 5 were double-switch patients and 2 underwent Senning-Bex/ Nikaidoh procedure). There were 5 Senning revisions, 1 pacemaker for spontaneous development of CHB 9.1 years

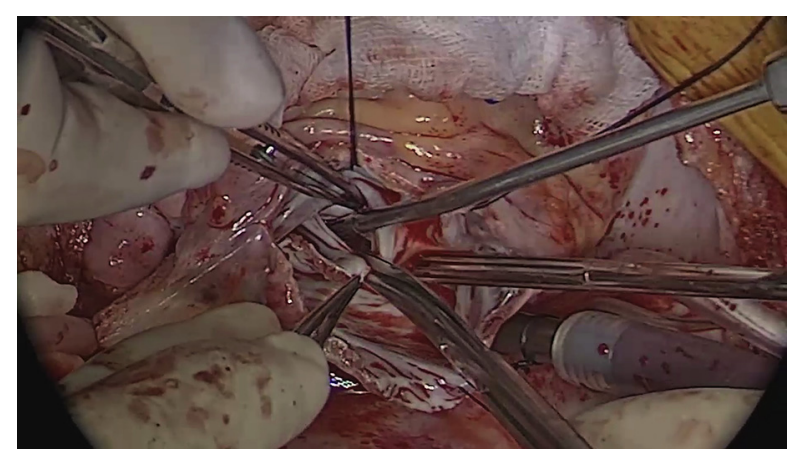

VIDEO 1. Modified Shumacker technique for Senning procedure. This video, with voiceover from the primary author, demonstrates the modified Shumacker technique for the Senning procedure utilized during an anatomic correction procedure at The Royal Children's Hospital Melbourne, Australia. Video available at: http://www.jtcvsonline.org/article/ S0022-5223(17)30588-3/addons. after anatomic correction, and 1 patient who required a Berlin heart and subsequent heart transplant 7 months after anatomic correction.

Cumulative incidence of late reoperation (excluding PPM revision) was $8 \%$ (95\% confidence interval [CI], 0\%-18\%), 29\% (95\% CI, 8\%-49\%), and 39\% (95\% CI, $12 \%-65 \%$ ) at 1,5 , and 10 years, respectively (Figure 2).

Further expression of these figures as event-free survival was $82 \%(95 \%$ CI, 69\%-98\%), 61\% (95\% CI, 44\%$86 \%$ ), and $51 \%(95 \% \mathrm{CI}, 31 \%-84 \%)$ at 1,5 , and 10 years, respectively (Figure 2). No late reinterventions or reoperations were associated with the Senning-Rastelli repair.

\section{Follow-up}

One international patient had no follow-up. Concurrent follow-up data were complete for 27 surviving patients with 156.3 patient-years for 31 patients and a median of 5.4 years for those surviving (range, 0.1-17.9 years).

There were 4 deaths: 1 early (Senning-Rastelli) and 3 late (3 double-switch). Kaplan-Meier analysis based on these patients yields a risk of death of $15 \%(95 \% \mathrm{CI}, 0 \%$ $27 \%$ ). The early death occurred in hospital, 33 days 
TABLE 3. Late reinterventions or reoperations associated with each patient

\begin{tabular}{|c|c|c|c|c|c|c|}
\hline $\begin{array}{c}\text { Anatomic } \\
\text { correction type }\end{array}$ & Reoperation or reintervention 1 & $\begin{array}{c}\text { Time since } \\
\text { anatomic } \\
\text { correction }(\mathbf{y})\end{array}$ & $\begin{array}{c}\text { Reoperation or } \\
\text { reintervention } 2\end{array}$ & $\begin{array}{c}\text { Time since } \\
\text { anatomic } \\
\text { correction }(y)\end{array}$ & $\begin{array}{c}\text { Further } \\
\text { reinterventions } \\
\text { or reoperations } \\
\end{array}$ & $\begin{array}{c}\text { Time since } \\
\text { anatomic } \\
\text { correction }(\mathbf{y})\end{array}$ \\
\hline DS & $\begin{array}{l}\text { Senning revision, PA aneurysm repair, } \\
\text { PPM revision }\end{array}$ & 0.4 & - & - & - & - \\
\hline DS & LVAD (Berlin heart) & 0.6 & Heart transplant & 0.6 & - & - \\
\hline DS & PPM revision & 0.9 & Senning revision & 2.1 & PPM revision & $2.2,8.5,13$ \\
\hline DS & PPM revision & 2.6 & - & - & - & - \\
\hline DS & PPM revision & 4.9 & PPM revision & 9.5 & - & - \\
\hline DS & Senning revision; PPM revision & 4.9 & - & - & - & - \\
\hline DS & PPM revision & 8.2 & - & - & - & - \\
\hline DS & PPM placement & 9.1 & - & - & - & - \\
\hline SBN & Senning revision, PPM revision & 1.8 & - & - & - & - \\
\hline SBN & Senning revision & 3.4 & - & - & - & - \\
\hline
\end{tabular}

following anatomic correction and was attributed to neurologic complications. The late deaths occurred 61, 103, and 587 days following anatomic correction. The first patient (double-switch with VSD closure, LVOT resection and TV/MV repair) presented with congestive heart failure with severe neoaortic root dilation and AR with functional MR. The condition rapidly progressed to multiple cardiac arrests. The second patient (double-switch with VSD closure and preoperative $\mathrm{PAB}$ ) developed progressive congestive cardiac failure. At autopsy the deterioration was attributed to obstructed pulmonary venous drainage in an area that was patent at corrective surgery. The third (double-switch with VSD closure, preoperative PAB, and pacemaker for congenital CHB) developed progressive systemic pulmonary hypertension several months after revision of the pulmonary venous baffle of the Senning despite no obstruction recurrence. The patient died of dominant right heart failure.

One double-switch patient with VSD closure had an aortic arch repair and $\mathrm{PAB}$ as a premature neonate. The double-switch was technically difficult and required 2 intraoperative revisions and extracorporeal membrane oxygenation to leave the operating room. A PPM was inserted for acquired CHB. Early reoperation was required for baffle dehiscence and MV repair for MR. The child deteriorated over 6 months and was subsequently listed for transplant; long-term LVAD support was required. At last follow-up 1.4 years following orthotopic transplant, the patient was described as active without limitations.

In 26 surviving patients with native hearts, LV and RV function was normal in 19 and 24 patients, respectively. Seven patients had LV dysfunction: mild in 5, moderate in 1 , and severe in 1 patient (Table 4). Longitudinal observations for these 7 patients have been demonstrated in Figure E2. The risk of LV dysfunction at follow-up was not linked to receiving a pacemaker at any stage (hazard ratio, 2.1; 95\% CI, 0.35-12.4; $P=.4$ ). Previous PAB for retraining was not related to late $\mathrm{LV}$ dysfunction (hazard ratio, $4.4 ; 95 \%$ CI, $0.8-25 ; P=.08$ ).

Freedom from death, heart transplantation, and reduced $\mathrm{LV}$ function moderate or greater was $81 \%(95 \% \mathrm{CI}$, 68\%-98\%), 77\% (95\% CI, 62\%-95\%), and 77\% (95\% CI, $62 \%-95 \%$ ) for all patients at 1,5 , and 10 years, respectively (Figure $\mathrm{E} 3, A$ ). If separated into groups, these figures translated to $79 \%(95 \% \mathrm{CI}, 62 \%-100 \%), 73 \%(95 \% \mathrm{CI}$, $55 \%-96 \%)$, and $73 \%(95 \%$ CI, 55\%-96\%) for double switch patients alone at 1,5 , and 10 years, respectively; and $91 \%(95 \% \mathrm{CI}, 75 \%-100 \%)$ for Senning-Rastelli or Senning/Bex-Nikaidoh patients at 1,5 , and 10 years (Figure E3, B).

Two patients (1 double-switch, 1 Senning-Rastelli) had a change from no AR preoperatively to moderate or greater at late follow-up. Longitudinal observations for these 2 patients have been demonstrated in Figure E2, $B$. Previous $\mathrm{PAB}$ was correlated with the need for aortic valve surgery or with having neo-AV regurgitation moderate or greater (hazard ratio, $8.5 ; 95 \% \mathrm{CI}, 0.95-76 ; P=.03$ ). TR improved or remained stable in all but 1 patient. Nine patients had mild MR, and 3 had moderate MR. Two patients had aortic root dilatation, which was moderate in a Senning-Rastelli patient and severe in a double-switch patient.

Senning pulmonary venous baffles were mildly obstructed in 2 patients ( 1 of these patients had required an early Senning revision), but no patients with the Shumacker Senning modification had obstruction or required revision. No Senning-Rastelli patients had obstructed conduits.

\section{DISCUSSION}

Anatomic correction is accepted as a surgical option for the management of patients with ccTGA to treat or prevent the failure of the systemic RV. Outcomes are encouraging but morbidity and mortality are attached to this approach. To further legitimize this approach, we seek to characterize the morbidity and mode of failure after anatomic correction to reduce morbidity and improve results. A work in 


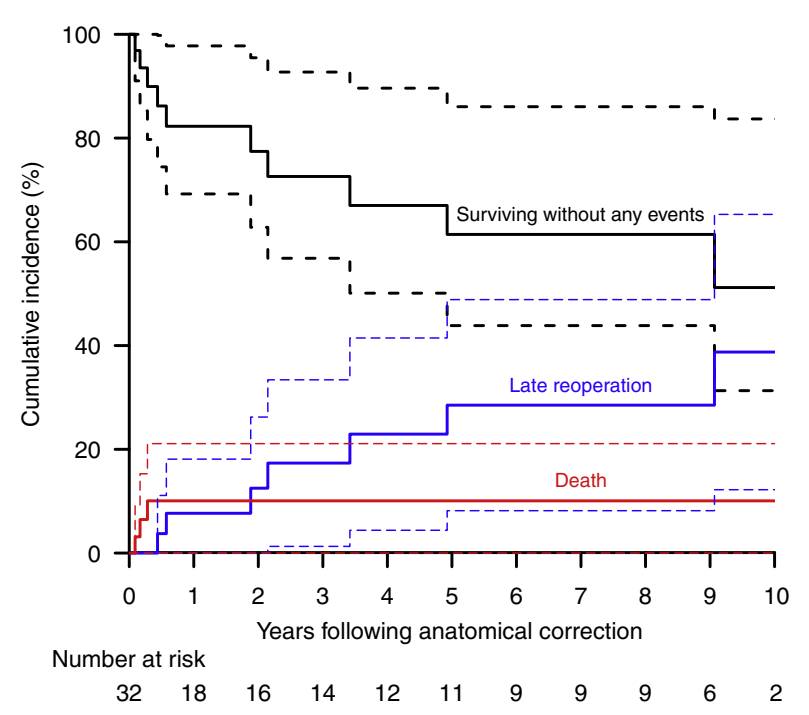

FIGURE 2. Competing risk plot for late reoperation and event-free survival following anatomic correction. The cumulative incidence of late reoperation (excluding PPM revision) was $8 \%$ (95\% confidence interval [CI], $0 \%-18 \%$ ), 29\% (95\% CI, 8\%-49\%), and 39\% (95\% CI, $12 \%$ $65 \%$ ) at 1,5 , and 10 years, respectively. Further expression of these figures as event-free survival was $82 \%(95 \% \mathrm{CI}, 69 \%-98 \%), 61 \%$ (95\% CI, $44 \%-86 \%$ ), and $51 \%(95 \%$ CI, 31\%-84\%) at 1,5 , and 10 years, respectively. The risk of death was $10 \%(95 \% \mathrm{CI}, 0 \%-21 \%)$ at 1,5 , and 10 years. The patient with transplantation was included in Figure 2 as part of the late reoperation category. Note that the dotted lines on each figure indicate the $95 \%$ CI for each solid line category.

\begin{tabular}{lccc}
\hline Time & $\begin{array}{c}\text { Surviving without any } \\
\text { event (black) }\end{array}$ & $\begin{array}{c}\text { Late } \\
\text { reoperation (blue })\end{array}$ & Death (red) \\
\hline $1 \mathrm{y}$ & $82 \%(69 \%-98 \%)$ & $8 \%(0 \%-18 \%)$ & $10 \%(0 \%-21 \%)$ \\
$5 \mathrm{y}$ & $61 \%(44 \%-86 \%)$ & $29 \%(8 \%-49 \%)$ & $10 \%(0 \%-21 \%)$ \\
$10 \mathrm{y}$ & $51 \%(31 \%-84 \%)$ & $39 \%(12 \%-65 \%)$ & $10 \%(0 \%-21 \%)$ \\
\hline
\end{tabular}

progress, this complex surgery requires continuous feedback to refine the timing, the surgical strategy, and the technical details.

The long-term survival and functional benefits after anatomic correction have been demonstrated in patients with severe preoperative TR or RV failure. ${ }^{8}$ This study confirms the improvement of RV and TV function following anatomic correction for ccTGA. Of the 26 surviving patients with follow-up data available and native hearts in situ, all but 1 have stable or improved TR when compared with their preoperative status at last follow-up, and RV function was normal in most patients.

Freedom from late reintervention and reoperation after anatomic correction has been investigated previously. Hraska and colleagues ${ }^{9}$ had the same procedure groups as used in this current series, with event-free survival rates of $95 \%, 57 \%$, and $57 \%$ at 1,5 , and 10 years, respectively.

With regard to atrial repair, reintervention rate for Senning revision was reported as $11 \%$ (of 113 patients) in 1 study, ${ }^{7}$ but lower in another. ${ }^{10}$ In our series, 6 patients required a Senning revision in the early or late postoperative period for pulmonary venous channel obstruction, of which 1 died during the late reoperation period from pulmonary hypertension without reobstruction. The Senning technique we use has evolved over the duration of the series. One goal is to remove the potential for stenosis of the superior vena cava often seen in classical Senning procedures and to increase the size of the atrial compliance chambers. ${ }^{11}$ Therefore, we have always used a patch to augment the systemic venous channel and augmented the outer part of the pulmonary venous channel. In this series we successively used patches of treated autologous pericardium, polytetrafluoroethylene $0.6 \mathrm{~mm}$, then autologous pediculated pericardium at that site. The last modification is itself a modification of the Shumacker technique ${ }^{6}$ where the pericardium is left in situ and a sutureless technique is used for the junction with the pulmonary veins incision. No patients who received this modification of the Shumacker technique during their Senning-developed stenosis. However, our followup time of these patients is short. Our first patient to undergo this modification was in early 2012 and our median followup time is only 0.59 years (range, 0.10-3.4 years).

With the double-switch, there is risk for neoaortic root enlargement and $\mathrm{AR} .{ }^{12}$ Of the patients who received the double-switch procedure, 1 has severe aortic root dilatation at recent follow-up. Another required atrioventricular repair during the early postoperative period for moderate AR. The PAB has also been discussed as a contributor to postoperative AR. ${ }^{9,10}$ Tightness of the band, ${ }^{10}$ or the proximity to the cusps, ${ }^{9}$ could be promoting factors. We found that having a PAB correlated with need for aortic valve surgery or with AR moderate or greater at follow-up. Two patients with severe subpulmonary stenosis should be outlined: the first had ccTGA with VSD and a pulmonary valve suitable for a double-switch after resection of the stenosis. After a simple postoperative course, he developed severe AR within weeks and died in hospital while being listed for semielective aortic valve replacement. The second patient had the same anatomy. He also had a very suitable valve after resection of the stenosis but, at surgery, we found the pulmonary sinuses and the valve so thin and weakened by the protection provided by the stenosis that we elected to do a BexNikaidoh procedure instead, with pulmonary translocation. Retrospectively, we should have used the same approach for the first patient.

With the Bex/Nikaidoh procedure, 6 Senning-Bex/ Nikaidoh repairs were performed with no deaths. Two developed iatrogenic CHB. Complete follow-up for this group was available, with a median of 2.1 years (range, 0.1-8.5 years) of follow-up. We found that a straddling MV did not constitute a contraindication for the SenningBex/Nikaidoh. Two patients from the Senning-Bex/ Nikaidoh group required a late Senning revision using the Shumacker modification. One was required due to stenosis 
TABLE 4. Patients with left ventricular (LV) dysfunction at follow-up

\begin{tabular}{|c|c|c|c|c|c|c|}
\hline $\begin{array}{c}\text { Letter } \\
\text { reference in } \\
\text { Figure E2 }\end{array}$ & Previous procedures & $\begin{array}{c}\text { Age at } \\
\text { procedure }(y) \\
\text { surgery type, } \\
\text { and year }\end{array}$ & $\begin{array}{l}\text { LV pressure at } \\
\text { correction }\end{array}$ & $\begin{array}{l}\text { Ventricular } \\
\text { function at } \\
\text { follow-up }\end{array}$ & $\begin{array}{l}\text { Pacing mode and } \\
\text { indication }\end{array}$ & Comments \\
\hline A & BT shunt $\times 2$ & 13 y SR 2002 & Systemic & $\begin{array}{l}\text { SF } 32 \% \\
\text { EF } 52 \%\end{array}$ & VVI back-up (not used) & - \\
\hline B & $\begin{array}{l}1 \text { sub-pulmonary } \\
\text { resection, DDD pacing } \\
1998 \\
2 \text { PAB training } 2002\end{array}$ & $\begin{array}{l}12 \text { y DS } 2006 \\
+ \text { aortic valve } \\
\text { replacement } \\
+ \text { PPM upgrade }\end{array}$ & $110 \%$ & EF $15 \%-20 \%$ & $\begin{array}{l}\text { DDD biventricular } \\
\text { iatrogenic }\end{array}$ & $\begin{array}{l}\text { Stable severe LV } \\
\text { dysfunction since } \\
\text { before surgery }\end{array}$ \\
\hline $\mathrm{C}$ & $\begin{array}{l}1 \text { neonatal } \mathrm{PAB} \text { (for } \\
\text { protection) }\end{array}$ & 1-y DS 1996 & Systemic & EF $42 \%$ & DDD iatrogenic & Low normal LV function \\
\hline $\mathrm{D}$ & $\begin{array}{l}1 \text { PAB } 2006 \\
2 \text { PAB tightening } 2007\end{array}$ & $\begin{array}{r}14-y \text { DS } 2009 \\
+ \text { aortic valve } \\
\text { replacement }\end{array}$ & Systemic & $\begin{array}{l}\text { EF } 50 \% \\
\text { SF } 26 \%\end{array}$ & None & $\begin{array}{l}\text { Ventricular function } \\
\text { improved after upgrade } \\
\text { of aortic valve to } 23 \mathrm{~mm}\end{array}$ \\
\hline $\mathrm{E}$ & $\begin{array}{l}1 \text { neonatal VVI pacing } \\
2 \text { PAB training, DDD } \\
\text { PPM } 2004\end{array}$ & $\begin{array}{l}\text { 4-y DS } 2005 \\
+ \text { LVAD (2 d) }\end{array}$ & $56 \%$ & EF $54 \%$ & $\begin{array}{l}\text { DDD biventricular } \\
\text { congenital }\end{array}$ & $\begin{array}{l}\text { Upgrade to biventricular } \\
\text { pacing improved } \\
\text { function }\end{array}$ \\
\hline $\mathrm{F}$ & $\begin{array}{l}1 \text { PAB } 2013 \\
2 \text { PAB tightening } 2013\end{array}$ & $\begin{array}{l}\text { 13-y DS } 2015 \\
+ \text { DDD }\end{array}$ & $90 \%$ & SF $25 \%$ & DDD congenital & $\begin{array}{l}\text { Ventricular function } \\
\text { declined over time }\end{array}$ \\
\hline G & - & $\begin{array}{l}\text { 0.4-y DS } 2008 \\
+ \text { sub-pulmonary } \\
\quad \text { resection } \\
+ \text { LVAD }(3 \mathrm{~d}) \\
+ \text { DDD }\end{array}$ & $60 \%$ & $\begin{array}{l}\text { EF } 50 \% \\
\text { SF } 31 \%\end{array}$ & DDD congenital & $\begin{array}{l}\text { Improved function with } \\
\text { new leads } 2013\end{array}$ \\
\hline
\end{tabular}

$L V$, Left ventricle; $B T$, Blalock-Taussig; $S R$, Senning-Rastelli; $S F$, shortening fraction; $E F$, ejection fraction; $V V I$, ventricular pacemaker; $D D D$, dual-chamber pacemaker; $P A B$, pulmonary artery band; $D S$, double switch; $P P M$, permanent pacemaker; $L V A D$, left ventricular assist device.

of the pulmonary venous pathway. The other was mild and performed electively in conjunction with a pacemaker replacement. In both, no recurrent narrowing was noted at follow-up. Experience with the Senning-Bex/Nikaidoh procedure is otherwise limited in the previous literature. $\mathrm{Hu}$ and colleagues ${ }^{13}$ had 4 patients with ccTGA and atrial situs solitus undergo the Senning-Bex/Nikaidoh procedure; there were no deaths, but 1 patient required extracorporeal membrane oxygenation. Hraska and colleagues ${ }^{9}$ had 1 patient with ccTGA with atrial situs inversus and an inlet VSD. We find that the added complexity of the Senning-Bex/ Nikaidoh over the Senning-Rastelli is justified because the LVOT is perfectly aligned, and any VSD is accessible and easily closed from the RV aspect. Moreover, because the best candidates have mild valvular pulmonary stenosis and a decent pulmonary orifice, a double translocation can be done and should prevent a need for reoperation. The Bex-Nikaidoh operation in ccTGA and situs solitus does not mean an obligatory heart block. We have been extremely careful to excise the pulmonary valve with as little LVOT muscle as possible.

There have also been concerns about deterioration in LV function following anatomic correction for ccTGA. $7,9,12,14$ In our series, there were 7 patients with reduced LV function: 5 had mild and stable dysfunction, 1 had moderate dysfunction, and 1 had severe dysfunction at last follow-up. Across these 7 patients, 6 had a doubleswitch, and 1 had a Senning-Rastelli procedure. The patient with severe dysfunction is the 1 who had subpulmonary resection in another hospital. He underwent LV retraining in our unit despite severe biventricular failure. He had an even pressure ratio before the double-switch but poor function bilaterally. This was considered a palliative procedure to delay transplantation. After 10 years, the patient is not listed for transplantation. For patients with full follow-up and native hearts in situ, we could not demonstrate that PAB for LV retraining or having a pacemaker was related to late LV dysfunction. However, there was often a combination of the 2; that is, patients with LV dysfunction who had a previous PAB and/or have a pacemaker in situ. We could not perform a multivariable analysis because of the small sample size. Review of our data revealed significant differences among patients in the pace of the training, the level of LV pressure reached before correction, and the age at first PAB. Quinn and colleagues ${ }^{15}$ observed that early results of the double-switch procedure in patients whose morphologic LV required training compared favorably with those of patients whose morphologic LV required no training. However, an increased risk of deterioration of morphologic LV function over time was observed in patients whose morphologic LV required training. This was found by other authors ${ }^{7,14}$ and more specifically in 
double-switch patients, as in this present series (although we found that the LV dysfunction was stable over time).

The natural incidence of complete heart block in ccTGA is approximately $1 \%$ to $2 \%$ per 100 patient-years. ${ }^{16}$ The management of pacing is an integral part of management of ccTGA. Summarized details of pacing systems are provided in Table E2. Seven patients had a pacemaker for conduction anomalies before or during the anatomic correction (of the 7, 1 was for iatrogenic CHB from a procedure before anatomic correction, 3 were for congenital $\mathrm{CHB}$, and the remainder for second-degree block). Eight patients required a pacemaker for $\mathrm{CHB}$ after anatomic correction: during the early reoperation period, 6 were for iatrogenic CHB and 1 had a ventricular pacemaker backup not used after recovery of normal sinus rhythm, whereas during the late reoperation period, 1 spontaneously developed CHB. Current knowledge of the conduction anatomy does not always prevent such events. ${ }^{8,9,17}$ In situs solitus, although there is often suspicion of an anterior node ${ }^{18}$ we have worked with the assumption of a normal posterior node in the presence of septal alignment (due to a small or atretic pulmonary trunk) as advocated by Hosseinpour and Ho. ${ }^{19}$ At our institution we have not made a practice of electrophysiology study to delineate the course of the conduction system before surgery. We are concerned that catheter manipulation could damage the vulnerable conduction system and would not necessarily allow atrioventricular block to be avoided at surgery. For all our patients with VSD we have used the technique advocated by De Leval and colleagues, ${ }^{20}$ with suturing on the RV side of the septum. As our management strategies have evolved, we have paid more attention to pacing lead position. We now use a biventricular pacing system (cardiac resynchronization therapy) every time a pacemaker is needed. In that configuration, the LV electrode is at the base between the left anterior descending and circumflex arteries, and the RV electrode is at the apex. With simple DDD pacemakers, the location of the ventricular electrode is paramount and should be at the LV apex. In 2 patients, moderately depressed LV function had improved secondarily to near normal (ejection fraction of $54 \%$ and $50 \%$, respectively) with the repositioning of the ventricular lead to the LV apex or introduction of biventricular pacing (Table 4). The conduction system in ccTGA is already vulnerable and the risk and management of iatrogenic CHB remains a significant challenge.

This series spans 19 years. It encompasses the introduction of several significant innovations in our speciality. The blood cardioplegia is the most important and has made this surgery achievable without the pressure of time. The range of complexity could be expanded to include MV surgery, aortic translocation, Senning modification, complex coronary translocation, and so on. The developing complexity is not a goal per se, but corresponds to a quest to achieve biventricular physiology whenever balanced ventricles are present. The theoretically significant physiologic superiority above a Fontan physiology can only be translated in our patients' quality of life and exercise ability if mortality is low, if the need for reoperation is limited and predictable, and if complications limiting the quality of the result are absent. The duration of this series, together with the literature available, has allowed us to identify 4 main categories of complication leading to reintervention and/ or death: the neo-AV regurgitation, the pulmonary venous pathway of the Senning, the LV dysfunction, and the iatrogenic atrioventricular block. We believe that we are now in control of the pulmonary venous pathway with the Shumacker modification. With regard to damage to the neoAV by $\mathrm{PAB}$, we orient our strategy toward early repair and avoiding PAB for shunt control. Similarly, we consider and have done neonatal/early infancy repairs for neonates or young infants with an intact ventricular septum and severe TR. Lastly, we believe that LV retraining should be initiated very early in life, with minimal gradient, to allow patients to progressively grow into their band. The LV dysfunction encountered in our series is mild, responded to repositioning of the pacing electrodes when this problem was identified, and is otherwise stable over time. Exclusively a double-switch issue, we are convinced that it is a training issue and not an intraoperative technical problem. The iatrogenic atrioventricular block seems to remain the last, inescapable challenge.

\section{Limitations}

This was a retrospective study spanning a long time frame. The learning curve and evolution of the strategy and the surgery (ie, introduction of aortic translocation or the Senning modification) together with the amalgamation of 3 different procedures make the series inhomogeneous. The statistical analysis is not strongly powered and does not allow us to draw strong definite inferences.

\section{CONCLUSIONS}

The anatomic correction in this series provided excellent functional outcomes with strictly normal LV function demonstrated in three-quarters of the survivors and mild dysfunction in most of the other quarter. Continuous technical improvement and understanding the causes of less-than-perfect result should reduce the significant need for reoperations and the risk of death or transplantation. Four issues have been identified at follow-up:

1. The status of the aortic valve. The PAB can damage the future aortic valve in patients who receive an arterial switch.

2. LV function can be abnormal in double-switch patients who need retraining. We suspect that PAB may provide inadequate LV training in older patients or when done too fast. Future strategies should avoid leading to that 
situation; the double-switch may be safer in infancy than later in life with PAB training. When required, the LV training should be initiated early in life and the patient should grow into a loose band.

3. The secondary stenosis of the lower aspect of the pulmonary venous pathway of the Senning has been responsible for half of the deaths and of almost all the reoperations not related to a pacemaker. The inception of the Shumacker modification of the Senning has provided stable venous pathways.

4. The risk of iatrogenic CHB remains a significant challenge. Meticulous attention to LV pacing lead position is required with growing interest for biventricular pacing.

\section{Conflict of Interest Statement}

Authors have nothing to disclose with regard to commercial support.

\section{References}

1. Sano T, Riesenfeld T, Karl TR, Wilkinson JL. Intermediate-term outcome after intracardiac repair of associated cardiac defects in patients with atrioventricular and ventriculoarterial discordance. Circulation. 1995;92(9 Suppl):II272-8.

2. Rutledge JM, Nihill MR, Fraser CD, Smith OE, McMahon CJ, Bezold LI. Outcome of 121 patients with congenitally corrected transposition of the great arteries. Pediatr Cardiol. 2002;23:137-45.

3. Hraska V, Duncan BW, Mayer JE Jr, Freed M, del Nido PJ, Jonas RA. Long-term outcome of surgically treated patients with corrected transposition of the great arteries. J Thorac Cardiovasc Surg. 2005;129:182-91.

4. Brawn WJ. Surgery for congenitally corrected transposition of the great arteries. In: Sabiston \& Spencer Surgery of the Chest. 8th ed. Philadelphia: Saunders/ Elsevier; 2010:2003-13.

5. Zoghbi WA, Enriquez-Sarano M, Foster E, Grayburn PA, Kraft CD, Levine RA, et al. Recommendations for evaluation of the severity of native valvular regurgitation with two-dimensional and Doppler echocardiography. J Am Soc Echocardiogr. 2003;16:777-802.

6. Tonkin IL, Allen RG, Casini M, Marin-Garcia J, Anthony CL, Bell ED, et al. Modified Shumacker repair of transposition of the great arteries. Surgical and angiocardiographic considerations. J Thorac Cardiovasc Surg. 1983;85:306-12.

7. Murtuza B, Barron DJ, Stumper O, Stickley J, Eaton D, Jones TJ, et al. Anatomic repair for congenitally corrected transposition of the great arteries: a single-institution 19-year experience. J Thorac Cardiovasc Surg. 2011;142: 1348-57.e1.

8. Shin'oka T, Kurosawa H, Imai Y, Aoki M, Ishiyama M, Sakamoto T, et al. Outcomes of definitive surgical repair for congenitally corrected transposition of the great arteries or double outlet right ventricle with discordant atrioventricular connections: risk analyses in 189 patients. J Thorac Cardiovasc Surg. 2007;133: 1318-28. 28.e1-4.

9. Hraska V, Mattes A, Haun C, Blaschczok HC, Photiadis J, Murin P, et al. Functional outcome of anatomic correction of corrected transposition of the great arteries. Eur J Cardiothorac Surg. 2011;40:1227-34.

10. Langley SM, Winlaw DS, Stumper O, Dhillon R, De Giovanni JV, Wright JG, et al. Midterm results after restoration of the morphologically left ventricle to the systemic circulation in patients with congenitally corrected transposition of the great arteries. J Thorac Cardiovasc Surg. 2003; 125:1229-41.

11. Derrick GP, Narang I, White PA, Kelleher A, Bush A, Penny DJ, et al. Failure of stroke volume augmentation during exercise and dobutamine stress is unrelated to load-independent indexes of right ventricular performance after the Mustard operation. Circulation. 2000;102(19 Suppl 3):III154-9.

12. Karl TR, Weintraub RG, Brizard CP, Cochrane AD, Mee RB. Senning plus arterial switch operation for discordant (congenitally corrected) transposition. Ann Thorac Surg. 1997;64:495-502.

13. Hu SS, Liu ZG, Li SJ, Shen XD, Wang X, Liu JP, et al. Strategy for biventricular outflow tract reconstruction: Rastelli, REV, or Nikaidoh procedure? J Thorac Cardiovasc Surg. 2008;135:331-8.

14. Duncan BW, Mee RB, Mesia CI, Qureshi A, Rosenthal GL, Seshadri SG, et al. Results of the double switch operation for congenitally corrected transposition of the great arteries. Eur J Cardiothorac Surg. 2003;24:11-9.

15. Quinn DW, McGuirk SP, Metha C, Nightingale P, de Giovanni JV, Dhillon R, et al. The morphologic left ventricle that requires training by means of pulmonary artery banding before the double-switch procedure for congenitally corrected transposition of the great arteries is at risk of late dysfunction. J Thorac Cardiovasc Surg. 2008;135:1137-44. 44.e1-2.

16. Simmons MA, Rollinson N, Fishberger S, Qin L, Fahey J, Elder RW Modern incidence of complete heart block in patients with l-looped ventricles: does univentricular status matter? Congenit Heart Dis. 2015;10: E237-42.

17. Hoashi T, Kagisaki K, Miyazaki A, Kurosaki K, Shiraishi I, Yagihara T, et al Anatomic repair for corrected transposition with left ventricular outflow tract obstruction. Ann Thorac Surg. 2013;96:611-20.

18. Anderson RH, Becker AE, Arnold R, Wilkinson JL. The conducting tissues in congenitally corrected transposition. Circulation. 1974;50:911-23.

19. Hosseinpour AR, McCarthy KP, Griselli M, Sethia B, Ho SY. Congenitally corrected transposition: size of the pulmonary trunk and septal malalignment. Ann Thorac Surg. 2004;77:2163-6.

20. De Leval MR, Bastos P, Stark J, Taylor JF, Macartney FJ, Anderson RH. Surgica technique to reduce the risks of heart block following closure of ventricular septal defect in atrioventricular discordance. J Thorac Cardiovasc Surg. 1979;78: 515-26.

Key Words: congenitally corrected transposition (ccTGA), arterial switch operation, Senning procedure, aortic translocation 


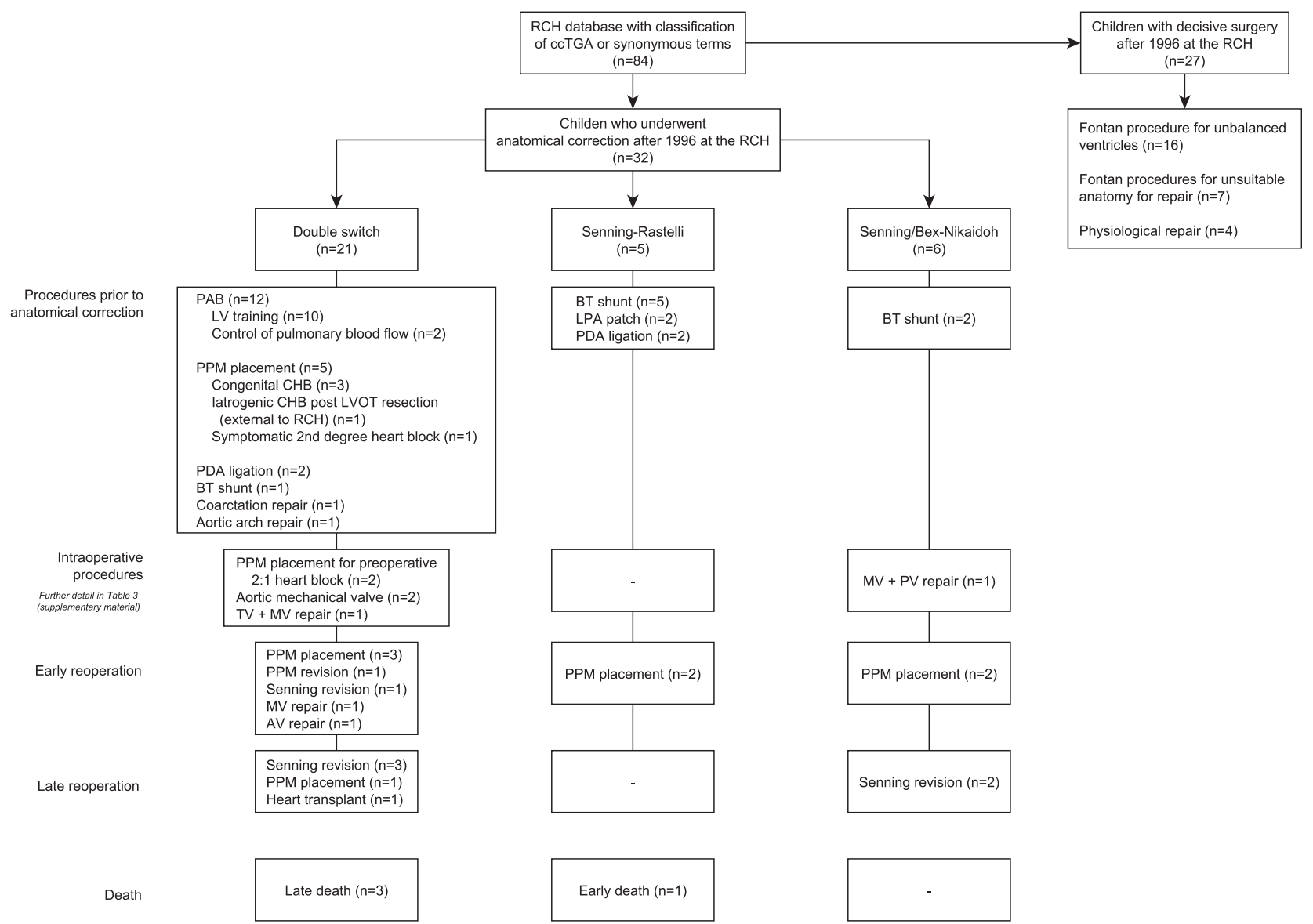

FIGURE E1. Block flowchart diagram of patients and procedures. This figure depicts the 32 patients of the study, separated into anatomic correction groups, and lists the procedures and interventions taken at various stages before and following anatomic correction. The number of deaths from each group is listed at the bottom of the diagram. $R C H$, Royal Children's Hospital Melbourne; $c c T G A$, congenitally corrected transposition of the great arteries; $P A B$, pulmonary artery band; $L V$, left ventricle; $P P M$, permanent pacemaker; $C H B$, complete heart block; $L V O T$, left ventricular outflow tract; $P D A$, patent ductus arteriosus; $B T$, Blalock-Taussig; $L P A$, left pulmonary artery; $T V$, tricuspid valve; $M V$, mitral valve; $P V$, pulmonary valve; $A V$, aortic valve. 

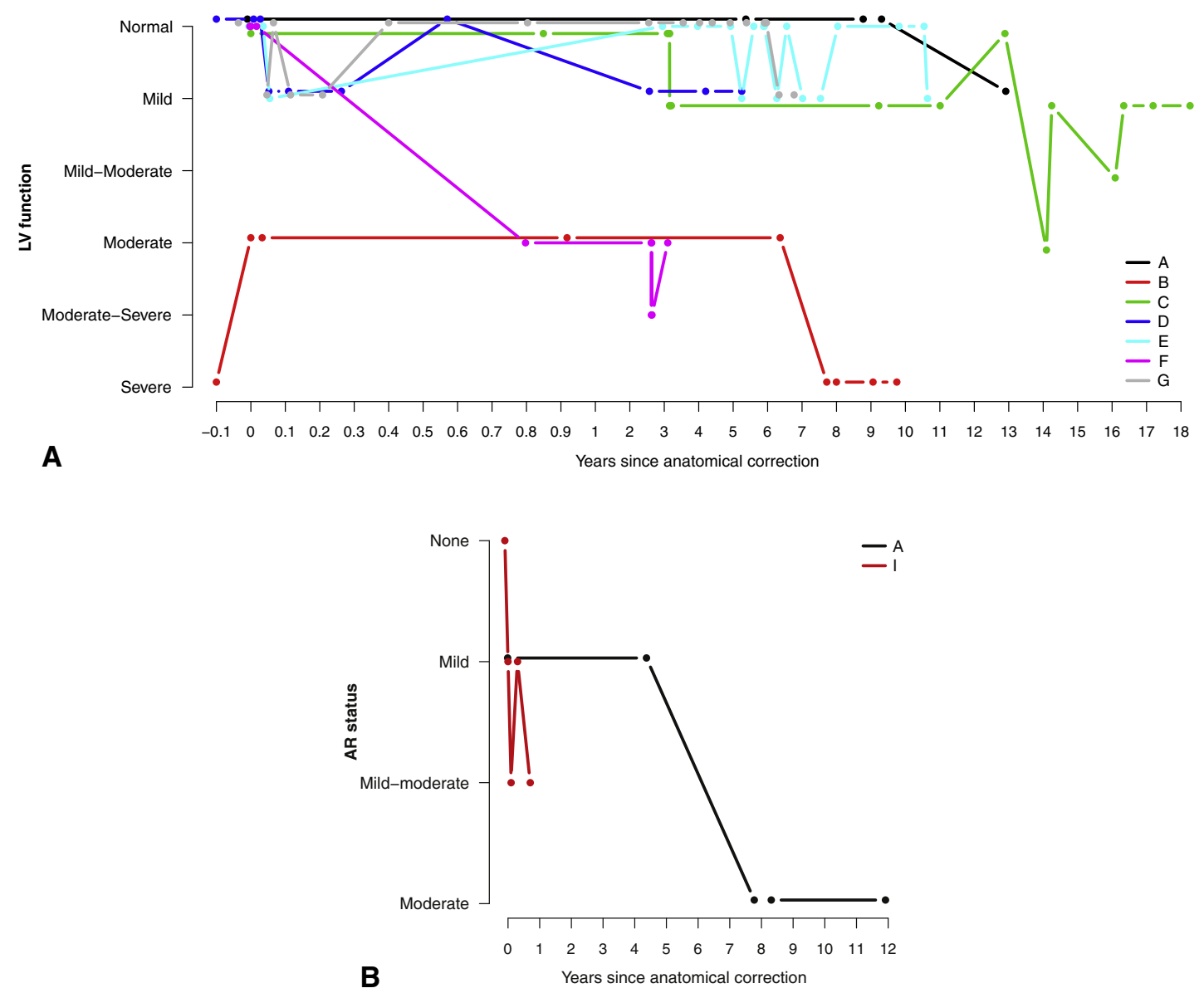

FIGURE E2. Longitudinal observation of postoperative left ventricle $(L V)$ function and aortic regurgitation. A, Longitudinal observations for postoperative $\mathrm{LV}$ function for children $(\mathrm{n}=7)$ noted to have mild or greater $\mathrm{LV}$ dysfunction at latest follow-up, with grading of LV function provided at various time points throughout their preceding follow-up. Letters in panel A correlate with those indicated in Table 4. B, Longitudinal observations for postoperative aortic regurgitation $(A R)$ for children $(\mathrm{n}=2)$ noted to have moderate or greater $\mathrm{AR}$ at latest follow-up, with grading of AR provided at various time points throughout their preceding follow-up. 


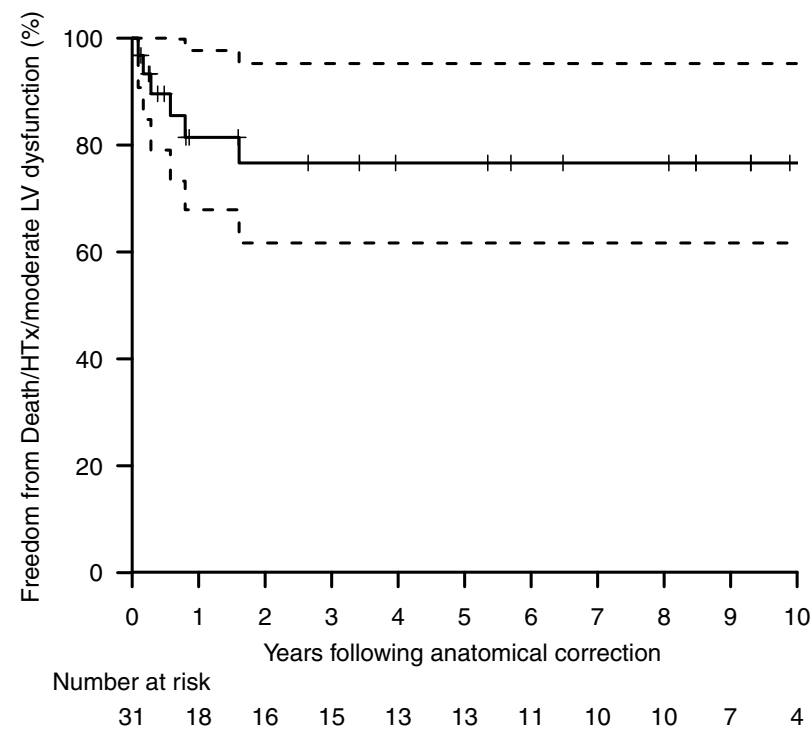

A

FIGURE E3. Freedom from death, heart transplantation, and moderate or greater left ventricle $(L V)$ function. A, Freedom from death, heart transplantation, and moderate or greater LV function was $81 \%$ (95\% confidence interval [CI], 68\%-98\%), 77\% (95\% CI, 62\%-95\%), and 77\% (95\% CI, 62\%-95\%) for all patients at 1, 5, and 10 years, respectively. B, If separated into groups, these freedom figures translated to 79\% (95\% CI, 62\%-100\%), 73\% (95\% CI, $55 \%-96 \%)$, and $73 \%(95 \% \mathrm{CI}, 55 \%-96 \%)$ for double switch patients alone at 1, 5, and 10 years, respectively; and $91 \%$ (95\% CI, $75 \%-100 \%)$ for Senning-Rastelli $(S R)$ or Senning/Bex-Nikaidoh $(S B N)$ patients at 1, 5, and 10 years. The dotted lines on each figure indicate the $95 \%$ CI for each solid line category. The above figures exclude a child who already had severe LV function before anatomic correction. HTx, Heart transplantation.

\begin{tabular}{lllr}
\hline Time & All patients & DS (blue) & SR/SBN (orange) \\
\hline $1 \mathrm{y}$ & $81 \%(68 \%-98 \%)$ & $79 \%(62 \%-100 \%)$ & $91 \%(75 \%-100 \%)$ \\
$5 \mathrm{y}$ & $77 \%(62 \%-95 \%)$ & $73 \%(55 \%-96 \%)$ & $91 \%(75 \%-100 \%)$ \\
$10 \mathrm{y}$ & $77 \%(62 \%-95 \%)$ & $73 \%(55 \%-96 \%)$ & $91 \%(75 \%-100 \%)$ \\
\hline
\end{tabular}


TABLE E1. Concomitant procedures at anatomic correction

Concomitant procedure

No. of patients

Ventricular septal defect closure

Pulmonary artery repair or reconstruction

Pacemaker placement

Neoaortic valve replacement

Mitral valve repair

Subpulmonary stenosis resection

Pulmonary translocation (Senning-Bex/Nikaidoh patients)

Tricuspid valve repair

Pulmonary valve repair

Patent ductus arteriosus ligation

Left coronary augmentation (segment of innominate artery)

Coarctation repair

TABLE E2. Details of children with pacemakers in situ

\begin{tabular}{llccll}
\hline Time of placement & $\begin{array}{c}\text { Operation } \\
\text { type }\end{array}$ & $\begin{array}{c}\text { No. of } \\
\text { systems }\end{array}$ & $\begin{array}{c}\text { Years paced } \\
\text { (to follow-up } \\
\text { or death) }\end{array}$ & $\begin{array}{c}\text { Most recent } \\
\text { pacemaker mode }\end{array}$ & Notes \\
\hline Before anatomic correction & DS & 4 & 14 & CRT & Congenital CHB \\
& DS & 5 & 18 & CRT & $\begin{array}{c}\text { Iatrogenic CHB from LVOT resection before } \\
\text { anatomic correction }\end{array}$ \\
& DS & 2 & 1.8 & DDD & Congenital CHB; deceased \\
& DS & 1 & 6.9 & DDD & Congenital CHB \\
At time of anatomic correction & DS & 2 & 8.5 & DDD & 2nd degree atrioventricular block \\
& DS & 1 & 0.8 & DDD & Preoperative 2nd degree atrioventricular block \\
& DS & 2 & 6.5 & DDD & Preoperative 2nd degree atrioventricular block \\
& SBN & 1 & 0.07 & CRT & Iatrogenic CHB \\
& SR & 1 & 0.07 & DDD & Iatrogenic CHB; deceased \\
& DS & 1 & 0.13 & DDD & Iatrogenic CHB; deceased \\
& DS & 1 & 1.9 & DDD & Iatrogenic CHB; heart transplant \\
& SBN & 2 & 3.9 & DDD & Back-up system placed, not used \\
& SR & 1 & 12 & VVI & Iatrogenic CHB \\
Late reoperation period & DS & 2 & 18 & DDD & Spontaneous CHB \\
\hline$D S$, Double switch; $C R T$, cardiac resynchronization therapy; $C H B$, complete heart block; $L V O T$, left ventricular outflow tract; $D D D$, dual-chamber pacemaker; $S B N$, Senning-Bex/
\end{tabular}

